\title{
The corrosion scenario in human body: Stainless steel 316L orthopaedic implants
}

\author{
Kean-Khoon Chew, Sharif Hussein Sharif Zein", Abdul Latif Ahmad \\ School of Chemical Engineering, Engineering Campus, Universiti Sains Malaysia, Penang, Malaysia; \\ *Corresponding Author: chhussein@eng.usm.my
}

Received 23 December 2011; revised 25 January 2012; accepted 7 February 2012

\begin{abstract}
As the world's populations increase and age, there is a parallel increase in the number of medical procedures addressed to bone related injuries. It is estimated that approximately 1 million of orthopaedic implant surgeries in association with total joint replacements are needed every year. This number is expected to double between 1999 and 2025 as a result of increasing numbers of musculoskeletal injuries (i.e., due to routine activities such as work, sport, etc.) and musculoskeletal diseases (i.e., such as osteoporosis, arthritis and bursitis due to increase age). Consequently, the increase demand for better quality of life has necessarily led people to opt for high quality orthopaedic devices for early recovery and speedy resumption of their routine activities. Unfortunately in the present time, it has been found that the current used orthopaedic implants have the tendencies to fail after long period of usage, due to the corrosion issue of implant in the human body. Therefore, this paper provides a simple overview about the corrosion issue of stainless steel (SS) $316 \mathrm{~L}$ as implants in human body. Electrophoretic deposition (EPD) of hydroxypaptite (HA) bioceramic was proposed as the approach to minimize the corrosion phenomena. Additionally, the corrosion testing of HA coated SS $316 \mathrm{~L}$ in comparison to pristine SS 316L was also performed and discussed.
\end{abstract}

Keywords: Corrosion; Metallic Implant; Stainless Steel; Electrophoretic Deposition; Hydroxyapatite

\section{INTRODUCTION}

It has been a customary in orthopaedic to employ medical grade stainless steel (SS) 316L as temporary implants since many decades ago [1]. This is because it offers the benefits such as mechanical properties relative to those of bone mineral, ease of fabrication and availability at low cost [2-4]. But, it was reported elsewhere that SS corrodes in vivo $[5,6]$, and causes the release of metal ions (e.g., iron (Fe), Cr, and Ni) [4,7-9]. Okazaki and Gotoh (2005) assessed that the replacement of $20 \mathrm{SS}$ Charnley hip arthroplasties in human body after $10-13$ years resulted in an accumulation of a considerably high metal ions concentration in body fluid in comparison with that without implant [10]; in which Ni contents in blood of $\sim 0.51 \mu \mathrm{g} / \mathrm{L}$, in plasma of $\sim 0.26 \mu \mathrm{g} / \mathrm{L}$ and in urine of $2.24 \mu \mathrm{g} / \mathrm{L}$, and $\mathrm{Cr}$ level in plasma of $\sim 0.19 \mu \mathrm{g} / \mathrm{L}$ were detected to be higher as compared with the control. These degradation products of corrosion can result in inflammatory response locally and systemically $[11,12]$. Locally, corrosion products have been associated with cessation of bone formation/growth, synovitis and loosening of artificial joint implants [13-15]; systemically, corrosion products may cause neoplasms [11,13]. For instance, a recent investigation reports that SS $316 \mathrm{~L}$ releases corrosion products above certain non-lethal concentrations and disturbs the proliferation/differentiation of osteoblastic human alveolar bone cell cultures in a dose-dependent manner [16].

Furthermore, a survey and examination of 50 failed indigenous SS implants retrieved from different patients in India was carried out over 4 years [8]. This study demonstrated that the classification of implant failures based on anatomical location showed that $74 \%$ failures were in the femoral, $8 \%$ in the knee, $4 \%$ in the tibia, $2 \%$ in the humerus and $6 \%$ in the radius and ulna. More than $90 \%$ of the SS $316 \mathrm{~L}$ implant devices were failed due to significant localised corrosion attack such as pitting and crevice corrosion [8]. The severity of corrosion attack increased with the implantation period. The pit-induced fatigue failure was found in the compression bone plate, while pit-induced stress corrosion cracking was observed in the intramedullary nail in which the edges of the nail were severely pitted and most of the cracks were found to be related with the pits $[2,17,18]$.

The above statements extremely urge the necessity for 
the development of new innovative SS implant materials as device design exhibiting high resistance characteristic to localised corrosion attack. Many attempts have been made to modify the surface of metal implants with ceramic coatings which intended to minimise the corrosion rate and arrest the release of metallic ions or corrosion products [19-28]. The literature searches show that the application of ceramic coatings to metal alloys can impart corrosion resistance, wear resistance and bioreactivity that are beneficial for medical devices [19-29]. Particularly, HA ceramic coatings on metallic substrates attract special attention from the research communities because of their excellent biocompatibility and bioactivity properties. HA is well known as the mineral contents of hard tissue (e.g., bone, dental enamel and dentine), thus it can directly form a bone bonding with hard tissues when used as a bone substitute material [30-32]. Unfortunately, its poor mechanical reliability (i.e., low fatigue resistance, weak tensile strength, elastic modulus mismatch and resultant stress shielding) has by some means limited its clinical applications [33]. For that reason, in the present study HA coating on SS 316L for orthopaedic applications were proposed in order to achieve a synergistic effect of bioactivity in conjunction with high mechanical strength [30,34]. More importantly, HA coating provides protection on SS to prevent corrosion by acting as a barrier against the release of metal ions into highly corrosive biological environment.

In both industry and academia, electrophoretic deposition (EPD) has received a great deal of attention as a promising predominant surface modification technique for the processing of advanced ceramic materials using the electrophoresis concept [35-38]. The increasing interest of the application of EPD is not only because of its high versatility to be used with different materials, but also due to its cost effectiveness requiring simple apparatus set-up [39]. In common, EPD is performed in a two electrode cell as illustrated schematically in Figure 1. Essentially, EPD is a two-step process $[38,40]$. In the first step, particles suspended in a liquid medium are forced to migrate towards an electrode under the effect of an electric field applied to the suspension (electrophoresis). In the second or deposition step, the particles are collected at one of the electrode and formed a relatively dense and homogeneous compact film via precipitation and coagulation.

In view of the fact that the present work is motivated by the concerns of the corrosion issue of current SS 316L implants. Therefore, the corrosion behaviour of the developed HA coated SS 316L samples by EPD has been preliminary characterized by using electrochemical techniques under simulated physiological human condition to monitor its corrosion potential in comparison to pristine SS 316L.

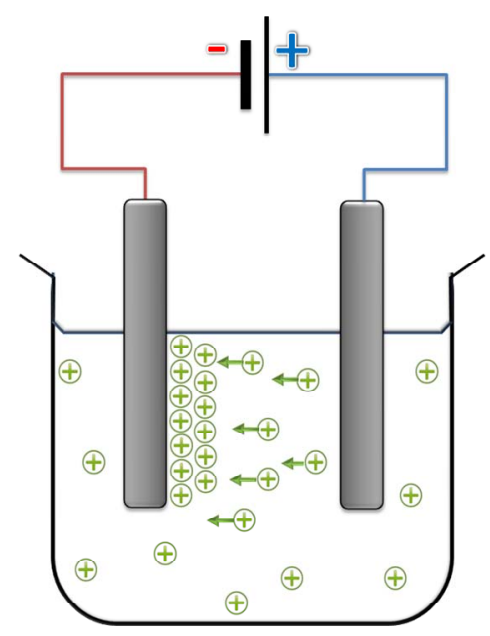

Figure 1. Schematic diagram of two electrodes cell for electrophoretic deposition demonstrating positively charged particles in suspension moving towards the negative electrode.

\section{METHOD AND MATERIALS}

\subsection{Electrophoretic Deposition (EPD) of Hydroxyapatite (HA)}

The HA aqueous suspension consisting of $4 \mathrm{~g} / \mathrm{L}$ commercially available HA powder (Aldrich) in de-ionised water $(18 \mathrm{M} \Omega \mathrm{cm})$ was prepared. Then, the HA suspension was stirred vigorously and adjusted to $\mathrm{pH}$ of 4 by the addition of acetic acid ( $\geq 99.7 \%$, Sigma-Aldrich). After stirring, the suspension was dispersed ultrasonically for 30 minutes using an ultrasonic processor (model: USG150). The fresh suspension was then immediately used for the EPD process without further aging. SS sheets of type $316 \mathrm{~L}$, with an effective surface area of $10 \times 10 \mathrm{~mm}^{2}$ and a thickness of $0.2 \mathrm{~mm}$, were used as both anode and cathode substrates. Prior to the EPD process, the SS 316L substrates were washed thoroughly with running de-ionised water, ultrasonically degreased in acetone and again rinsed thoroughly with de-ionised water, followed by drying in an air oven at $60^{\circ} \mathrm{C}$. The deposition process was performed on one side of the SS 316L substrate; the other side and edges were masked with a non-conducting vinyl tape. Both SS 316L substrates were immersed in the HA suspension inside a $50 \mathrm{ml}$ borosilicate glass beaker, and the separation distance between them was adjusted to 10 $\mathrm{mm}$ for all experiments. The EPD process was conducted for a deposition time of $550 \mathrm{~s}$, and the cell potential voltage at $30 \mathrm{~V}$.

\subsection{Electrochemical Evaluation of Corrosion Behaviour Studies}

The electrochemical evaluation of the corrosion behaviour of the HA coated SS was performed using a VMP3 
multi-potentiostat system (Bio-Logic, SAS, France) with analysis software (EC-Lab ${ }^{\circledR}$ Version 9.0). In this threeelectrode system, a saturated calomel electrode (SCE) was used as the reference electrode, a platinum electrode was the auxiliary electrode and the prepared sample was connected as working electrode. The physiological simulated body fluid (SBF) was prepared using de-ionised water and analytical grade reagents according to protocol presented by Kuboko and his co-workers [41,42], was used as the electrolyte. In order to simulate the conditions of the human body, the SBF solution was maintained at a temperature of $37^{\circ} \mathrm{C} \pm 1{ }^{\circ} \mathrm{C}$ and a $\mathrm{pH}$ of 7.4. It was also deaerated with pure argon (Ar) gas throughout the experiment. The coated area of the sample that was exposed to the corrosion study had dimensions of $10 \times 10 \mathrm{~mm}^{2}$. The evaluation of the corrosion behaviour of the HA coated and pristine SS 316L samples was performed by measuring the open circuit potential (OCP). The corrosion potential was measured as a function of the immersion time.

\section{RESULTS AND DISCUSSION}

One simple approach to examine the corrosion behaviour of a metallic material is by monitoring its' OCP-time characteristics [43]. OCP values measured using the linear polarisation technique is the potential values recorded over a period of time in which no current is applied to the sample. In this regard, the protective nature of HA coating of the present investigation work could be accessed from the OCP-time values recorded in comparison with pristine SS 316L. The OCP study as a function of time of both HA coated $316 \mathrm{~L}$ and pristine $316 \mathrm{~L}$ was presented in Table 1. It was observed that the OCP values of HA coated SS 316L were increasing gradually. This observation suggests that the HA coating developed was stable and successfully providing an protective insulating layer over the surface of SS 316L. On the other hand, a drop of OCP values was demonstrated by the pristine SS 316L sample, indicating that dissolution of metal ions took place at the SS $316 \mathrm{~L}$ surface.

\section{CONCLUSION}

In short, the corrosion issue of implant is not something that one usually thinks about until it becomes a personal health issue for most of us. It is becoming clear that a continuing need for stringent research and development of new technologies for improving the performance characteristics of current available SS 316L implant is very significant. Finally, these risks can be eventually managed and eliminated one day.

\section{ACKNOWLEDGEMENTS}

The authors acknowledge the financial support provided by the Uni-
Table 1. Open circuit potential variations of HA coated SS 316L and pristine SS 316L.

\begin{tabular}{ccc}
\hline \multirow{2}{*}{ Time (mins) } & \multicolumn{2}{c}{ Open Circuit Potential (OCP) } \\
\cline { 2 - 3 } 1 & HA coated SS 316L & Pristine SS 316L \\
\hline 2 & -0.0401 & -0.2819 \\
3 & -0.0370 & -0.2845 \\
4 & -0.0346 & -0.2870 \\
5 & -0.0323 & -0.2899 \\
6 & -0.0301 & -0.2927 \\
7 & -0.0284 & -0.2949 \\
8 & -0.0268 & -0.2978 \\
9 & -0.0253 & -0.3001 \\
10 & -0.0240 & -0.3022 \\
11 & -0.0227 & -0.3048 \\
12 & -0.0216 & -0.3074 \\
13 & -0.0205 & -0.3096 \\
14 & -0.0197 & -0.3115 \\
15 & -0.0186 & -0.3131 \\
\hline
\end{tabular}

versiti Sains Malaysia (RU Grant) and Kean Khoon Chew also acknowledges Fellowship by Universiti Sains Malaysia and Research University Postgraduate Research Grant Scheme (USM-RU-PRGS).

\section{REFERENCES}

[1] Mudali, U.K., Sridhar, T.M. and Raj, B. (2003) Corrosion of bio implants. Sadhana-Academy Proceedings in Engineering Sciences, 28, 601-637.

[2] Sivakumar, M., Kamachi Mudali, U. and Rajeswari, S. (1995) Investigation of failures in stainless steel orthopaedic implant devices: pit-induced fatigue cracks. Journal of Materials Science Letters, 14, 148-151. doi:10.1007/BF00456573

[3] Gopi, D., Prakash, V.C.A. and Kavitha, L. (2009) Evaluation of hydroxyapatite coatings on borate passivated 316L SS in Ringer's solution. Materials Science \& Engineering C-Biomimetic and Supramolecular Systems, $\mathbf{2 9}$ 955-958.

[4] Sridhar, T.M., Mudali, U.K. and Subbaiyan, M. (2003) Preparation and characterisation of electrophoretically deposited hydroxyapatite coatings on type 316L stainless steel. Corrosion Science, 45, 237-252. doi:10.1016/S0010-938X(02)00091-4

[5] Dobbs, H.S. and Scales, J.T., (1979) Fracture and corrosion in stainless steel total hip replacement stem. In: Syrett, B.C. and Acharya, A. Eds., Corrosion and Degradation of Implanted Materials, American Society for 
Testing and Materials, West Conshohocken, 254-258.

[6] Sutow, E.J. and Pollack, S.R., (1981) Biocompatibility of clinical implant materials I. In: William, D.F. Eds., CRC Press, Boca Raton, 45-48.

[7] Gurappa, I. (2002) Development of appropriate thickness ceramic coatings on $316 \mathrm{~L}$ stainless steel for biomedical applications. Surface and Coatings Technology, 161, 7078. doi:10.1016/S0257-8972(02)00380-8

[8] Sivakumar, M. and Rajeswari, S. (1992) Investigation of failures in stainless-steel orthopaedic implant devices: Pitinduced-stress-corrosion cracking. Journal of Materials Science Letters, 11, 1039-1042. doi:10.1007/BF00729754

[9] Tüken, T., (2006) Polypyrrole films on stainless steel. Surface and Coatings Technology, 200, 4713-4719. doi:10.1016/j.surfcoat.2005.04.011

[10] Okazaki, Y. and Gotoh, E. (2005) Comparison of metal release from various metallic biomaterials in vitro. Biomaterials, 26, 11-21.

doi:10.1016/j.biomaterials.2004.02.005

[11] Patterson, S.P., Daffner, R.H. and Gallo, R.A. (2005) Electrochemical corrosion of matal implants. American Roentgen Ray Society, 184, 1219-1222.

[12] Silver, F. and Doillon, C., (1989) Biocompatibility: Interactions of biological and implantable materials, $\mathrm{VCH}$ Publishers, New York.

[13] Jacobs, J.J., Gilbert, J.L. and Urban, R.M. (1998) Corrosion of metal orthopaedic implants. Journal of Bone and Joint Surgery-American Volume, 80A, 268-282.

[14] Kong, H., Wilkinson, J.L., Coel, J.Y., Gu, X., Urness, M., Kim, T.H. and Bass, J.L., (2002) Corrosive behaviour of amplatzer devices in experimental and biological environments. Cardiol Young, 12, 260-265. doi:10.1017/S1047951102000562

[15] Fernandes, M.H. (1999) Effect of stainless steel corrosion products on in vitro biomineralization. Journal of Biomaterials Applications, 14, 113-168.

[16] Costa, M.A. and Fernandes, M.H., (2000) Proliferation/ differentiation of osteoblastic human alveolar bone cell cultures in the presence of stainless steel corrosion products. Journal of Materials Science: Materials in Medicine, 11, 141-153. doi:10.1023/A:1008975507654

[17] Sivakumar, M., Mudali, U.K. and Rajeswari, S. (1993) Compatibility of ferritic and duplex stainless steels as implant materials. Journal of Materials Science, 28, 60816086. doi:10.1007/BF00365025

[18] Sivakumar, M., Mudali, U.K. and Rajeswari, S. (1993) Pit-induced corrosion failures in stainless steel orthopaedic implant devices. Proceeding of 12th International Corrosion Congress, Houston, 1949-1956.

[19] Lemons, J.E. (1998) Surface modifications of surgical implants. Surface and Coatings Technology, 103-104, 135137.

[20] Gurrappa, I. (2001) Corrosion and its importance in selection of materials for biomedical applications. Corrosion Prevention and Control, 48, 23-37.

[21] González-Carrasco, J.L., Escudero, M.L., Chao, J. and García-Alonso, M.C. (1998) Thermal oxidation treatments in the development of new coated biomaterials: Application to the MA 956 superalloy. Materials and Manufacturing Processes, 13, 431-443. doi:10.1080/10426919808935260

[22] Montenero, A., Gnappi, G., Ferrari, F., Cesari, M., Salvioli, E., Mattogno, L., Kaciulis, S. and Fini, M., (2000) Sol-gel derived hydroxyapatite coatings on titanium substrate. Journal of Materials Science, 35, 2791-2797. doi:10.1023/A:1004738900778

[23] Feng, B., Chen, J.Y. and Zhang, X.D. (2001) Calcium phosphate coating on titanium induced by phosphating. Key Engineering Materials, 192-195, 167-170. doi:10.4028/www.scientific.net/KEM.192-195.167

[24] Gao, W., Liu, Z. and Li, Z., (2001) Nano- and microcrystal coatings and their high-temperature applications. Advanced Materials (Weinheim, Germany), 13, 1001-1004. doi:10.1002/1521-4095(200107)13:12/13<1001::AID-A DMA1001>3.0.CO;2-V

[25] Kawahara, H. (1987) Bioceramics for hard tissue replacements. Clinical Materials, 2, 181-206. doi:10.1016/0267-6605(87)90044-8

[26] Ding, X., Yamashita, K. and Umegaki, T., (1995) Coating of calcium phosphate on alumina ceramics by electrophoretic deposition. Nippon Seramikkusu Kyokai Gakujutsu Ronbunshi/Journal of the Ceramic Society of Japan, 103 (1200), 867-869. doi:10.2109/jcersj.103.867

[27] Kim, T.N., Feng, Q.L., Luo, Z.S., Cui, F.Z. and Kim, J.O., (1998) Highly adhesive hydroxyapatite coatings on alumina substrates prepared by ion-beam assisted deposition. Surface and Coatings Technology, 99, 20-23. doi:10.1016/S0257-8972(97)00121-7

[28] Oh, K.T. and Park, Y.S. (1998) Plasma-sprayed coating of hydroxylapatite on super austenitic stainless steels. Surface and Coatings Technology, 110, 4-12. doi:10.1016/S0257-8972(98)00537-4

[29] Santos, J.D.S. and Monteiro, F.J. (1990) Wear behaviour of stainless steel after $\mathrm{Al}_{2} \mathrm{O}_{3}$ plasma spraying for biomedical applications. Surface Engineering, 6, 209-212.

[30] Xiao, X.F. and Liu, R.F. (2006) Effect of suspension stability on electrophoretic deposition of hydroxyapatite coatings. Materials Letters, 60, 2627-2632. doi:10.1016/j.matlet.2006.01.048

[31] White, A.A., Best, S.M. and Kinloch, I.A., (2007) Hydroxyapatite-carbon nanotube composites for biomedical applications: A review. International Journal of Applied Ceramic Technology, 4, 1-13. doi:10.1111/j.1744-7402.2007.02113.x

[32] Suchanek, W. and Yoshimura, M., (1998) Processing and properties of hydroxyapatite-based biomaterials for use as hard tissue replacement implants. Journal of Materials Research, 13, 94-117. doi:10.1557/JMR.1998.0015

[33] Deeb, M.E. and Holmes, R.E., (1989) Tissue response to facial contour augmentation with dense and porous hydroxyapatite in rhesus monkeys. Journal of Oral and Maxillofacial Surgery, 47, 1282-1289. doi:10.1016/0278-2391(89)90725-8

[34] Lynn, A.K. and DuQuesnay, D.L., (2002) Hydroxyapatite-coated Ti 6Al 4V Part 1: The effect of coating thick- 
ness on fatigue behaviour. Biomaterials, 23, 1937-1946. doi:10.1016/S0142-9612(01)00321-0

[35] Boccaccini, A.R., Roether, J.A., Thomas, B.J.C., Shaffer M.S.P., Esther, C., Erick, S. and Jane, M.E., (2006) The electrophoretic deposition of inorganic nanoscaled materials: A review. Journal of the Ceramic Society of Japan, 14, 1-14. doi:10.2109/jcersj.114.1

[36] Boccaccini, A.R. and Zhitomirsky, I., (2002) Application of electrophoretic and electrolytic deposition techniques in ceramics processing. Current Opinion in Solid State \& Materials Science, 6, 251-260. doi:10.1016/S1359-0286(02)00080-3

[37] Boccaccini, A.R., Cho, J., Roether, J.A., Thomas, B.J.C., Jane Minay, E. and Shaffer, M.S.P., (2006) Electrophoretic deposition of carbon nanotubes. Carbon, 44, 31493160. doi:10.1016/j.carbon.2006.06.021

[38] Van der Biest, O.O. and Vandeperre, L.J., (1999) Electrophoretic deposition of materials. Annual Review of Materials Science, 29, 327-352. doi:10.1146/annurev.matsci.29.1.327

[39] Besra, L. and Liu, M., (2007) A review on fundamentals and applications of electrophoretic deposition (EPD). Progress in Materials Science, 52, 1-61. doi:10.1016/j.pmatsci.2006.07.001

[40] Zhitomirsky, I., (2006) Electrophoretic deposition of organic-inorganic nanocomposites. Journal of Materials Science, 41, 8186-8195. doi:10.1007/s10853-006-0994-7

[41] Kokubo, T., Ito, S., Huang, Z.T., Hayashi, T., Sakka, S., Kitsugi, T. and Yamamuro, T., (1990) Ca,P-rich layer formed on high-strength bioactive glass-ceramic A-W. Journal of Biomedical Materials Research, 24, 331-343. doi: $10.1002 / \mathrm{jbm} .820240306$

[42] Kokubo, T., Kushitani, H., Sakka, S., Kitsugi, T. and Yamamuro, T., (1990) Solutions able to reproduce in vivo surface-structure changes in bioactive glass-ceramic AW3. Journal of Biomedical Materials Research, 24, 721734. doi:10.1002/jbm.820240607

[43] Al-Mobarak, N.A., Al-Swayih, A.A. and Al-Rashoud, F.A., (2011) Corrosion behavior of Ti-6Al-7Nb alloy in biological solution for dentistry applications. International Journal of Electrochemical Science, 6, 2031-2042. 